

Bulletin du centre d'études médiévales d'Auxerre | BUCEMA

Hors-série $n^{\circ} 8 \mid 2015$

Au seuil du cloître : la présence des laïcs (hôtelleries, bâtiments d'accueil, activités artisanales et de services) entre le Ve et le XII ${ }^{\mathrm{e}}$ siècle

\title{
Les laïcs aux portes du cloître
}

Introduction

Christian Sapin

\section{(2penEdition}

Journals

Édition électronique

URL : https://journals.openedition.org/cem/13689

DOI : $10.4000 /$ cem.13689

ISSN : 1954-3093

Éditeur

Centre d'études médiévales Saint-Germain d'Auxerre

Référence électronique

Christian Sapin, «Les laïcs aux portes du cloître », Bulletin du centre d'études médiévales d'Auxerre I BUCEMA [En ligne], Hors-série n 8 | 2015, mis en ligne le 28 janvier 2015, consulté le 04 mars 2023. URL : http://journals.openedition.org/cem/13689; DOI : https://doi.org/10.4000/cem.13689

Ce document a été généré automatiquement le 4 mars 2023.

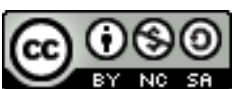

Creative Commons - Attribution - Pas d'Utilisation Commerciale - Partage dans les Mêmes Conditions 4.0 International - CC BY-NC-SA 4.0

https://creativecommons.org/licenses/by-nc-sa/4.0/ 


\title{
Les laïcs aux portes du cloître
}

\author{
Introduction
}

\section{Christian Sapin}

1 À la suite de découvertes archéologiques et de questions posées par l'organisation même des bâtiments au contact des laïcs, nous avons retenu, pour cette troisième rencontre monastique, la question de «la présence des laïcs au seuil du cloître ».

2 Présence et accueil, nécessités et ouvertures, quelle place pour les laïcs aux portes du monastère? Ceci pose les problèmes des limites et de la réalité de la

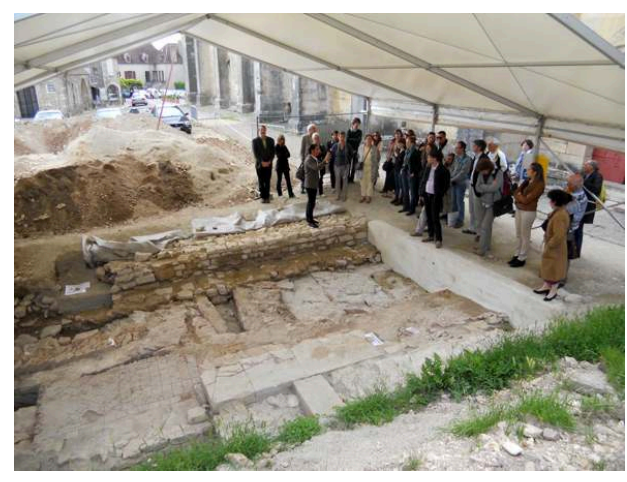
clôture, mais également des installations temporaires ou pérennes. Plus précisément, il s'agit de comprendre le rôle de la porterie, la place des hôtelleries et hospices, mais également les questions liées à l'artisanat et, d'une manière générale, au travail spécialisé non pris en charge par les moines.

3 Comme pour les rencontres précédentes, nous n'avons pas cherché à faire un état complet de la situation, mais simplement à reposer et approfondir certaines questions, à partir d'exemples concrets rencontrés dans le cadre du programme collectif de recherche ( $\mathrm{PCR}$ ) sur "les premiers monastères en Bourgogne et Franche-Comté ", élargies à un paysage monastique plus important, au-delà de nos frontières. On sait par expérience que les avancées des connaissances ne sont pas graduelles, mais ressortent souvent de confrontations d'étude de cas entre archéologues, historiens et historiens de l'art.

4 Nous aurions souhaité rester sur le haut Moyen Âge pour l'ensemble des exemples archéologiques et monumentaux, mais nous devons admettre que, dans beaucoup de cas, tout du moins pour les constructions, les éléments conservés nous portent plutôt vers les $\mathrm{XI}^{\mathrm{e}}$-XII ${ }^{\mathrm{e}}$ siècles. On retrouve toutefois le haut Moyen Âge à travers les activités artisanales, où les laïcs semblent avoir joué un rôle déterminant dans l'économie des 
monastères, comme on peut le déduire du Statut de 822 , où Adalhard de Corbie distingue l'activité des laïcs infra monasterium et extra monasterium.

Pour accueillir cette troisième rencontre d'études monastiques, nous avons choisi le site de Vézelay afin de profiter, notamment, de la vue des fouilles alors en cours sur l'emplacement du cloître et avant le rebouchage du site. Le choix de Vézelay est aussi symbolique des rapports, souvent conflictuels, entre la communauté monastique et celle des laïcs du bourg ${ }^{1}$. Les journées, qui se sont déroulées dans un climat cordial par rapport à celui du XII ${ }^{e}$ siècle, ont eu lieu dans la salle communale, dite "gothique ". Cette salle se trouvait à l'origine dans l'une des grandes demeures de bourgeois de Vézelay, qui édifièrent plusieurs de ces constructions civiles dans la seconde moitié du $\mathrm{XII}^{\mathrm{e}}$ siècle et au siècle suivant, le long des trois grandes rues menant à l'abbatiale. Ainsi, nous étions placés " du côté des laïcs ». En nous penchant dans la rue, nous aurions vu, à l'époque, à quelques dizaines de mètres à l'est, les murs de clôture de l'abbaye. Aujourd'hui, l'accès à l'abbatiale est toujours le même. Si, au sud, la porterie a disparu, laissant place à un vide longtemps occupé par les voitures des visiteurs, avec les fouilles récentes, le carré claustral retrouve ses dimensions et l'on peut saisir spatialement la transition des anciens espaces dévolus aux moines, avec, à l'est, les vestiges des anciens bâtiments : salle du chapitre et dortoir devenu musée.

À Vézelay, on sait, grâce aux sources et à la Chronique d'Hugues de Poitiers, que les laïcs ont été très tôt en opposition avec le pouvoir monastique, au point d'assassiner l'un des abbés, Artaud, au début du XII ${ }^{e}$ siècle. Au sein de la cité, qui compte, dès la fin du $\mathrm{XII}^{\mathrm{e}}$ siècle, deux églises paroissiales, Saint-Pierre et Saint-Étienne, le poids et les prérogatives des laïcs restent très forts jusqu'au XvIII ${ }^{\mathrm{e}}$ siècle. On peut encore le sentir de nos jours quand surgissent dans les débats publics des conflits de parole, notamment pour ceux qui défendent ce qu'ils considèrent être des acquis de la Révolution, en particulier l'accès aux terrasses orientales, celles où se trouvait le palais abbatial. En dépit de l'actualité archéologique, on est encore loin à Vézelay, où les recherches reprennent seulement, de pouvoir reconstituer matériellement (comme dans le plan de Saint-Gall) tous les éléments traduisant la présence des laïcs, telle que les communications de ces journées la présentent pour plusieurs sites. Après une relecture critique des sources, les porteries, les hôtelleries, les lieux de service et d'activités artisanales trouvent une consistance matérielle grâce à l'archéologie de plusieurs sites, pour certains inédits, tant en France, avec Hamage, Cluny, Jumièges, Marmoutier ou Saint-Claude, ou qu'en Europe, bien représentée, de l'Irlande à l'Italie en passant par la Belgique. 
Vézelay, visite du chantier de fouilles du cloître sous la conduite de Fabrice Henrion (cl. David Vuillermoz).

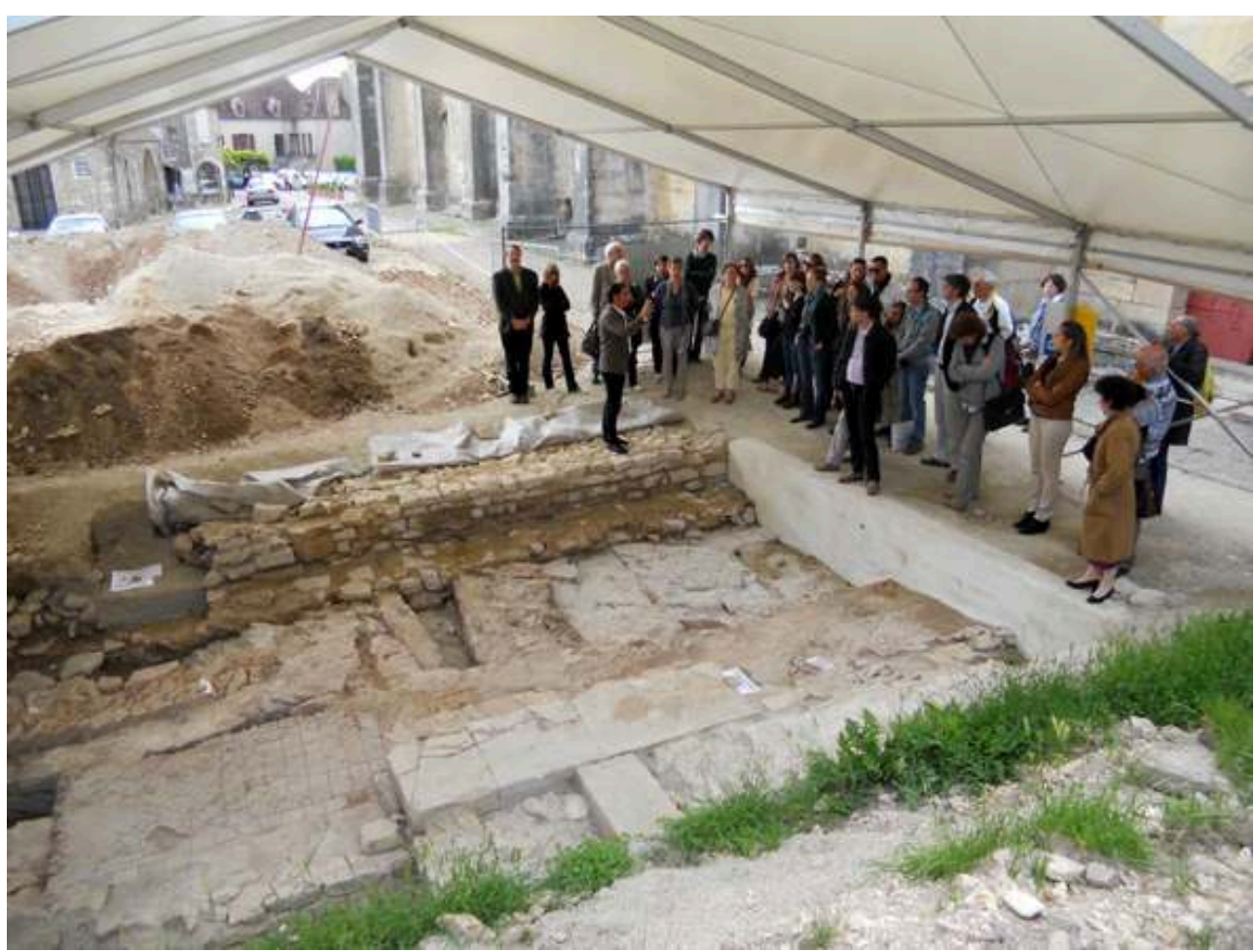

\section{NOTES}

1. Cf. B. BEYER DE RYKE, "Sérénité et fureur à Vézelay au Moyen Age ", in A. DIERKENS et A. MORELLI (dir.), Topographie du sacré. L'emprise religieuse sur l'espace, Bruxelles, 2008, p. 91-105.

\section{INDEX}

Index géographique : France/Vézelay

Mots-clés : laïc, cloître 
AUTEUR

CHRISTIAN SAPIN

Université de Bourgogne, UMR Artehis 